\title{
Biomechanical analysis of marathon shoes applied to NESTFIT technology
}

\author{
Seung-Bum Park ${ }^{1 *}$, Kyung-Deuk Lee ${ }^{1}$, Dae-Woong Kim, Jung-Hyeon Yoo ${ }^{1}$, Kyung-Hun Kim', Jin-Hoon Kim² \\ From 4th Congress of the International Foot and Ankle Biomechanics (i-FAB) Community \\ Busan, Korea. 8-11 April 2014
}

The purpose of this study was to analyze foot pressure distribution of marathon shoes to which NESTFIT Technology was applied. As for marathon, shoes play a vital role in shortening records. However, they also might become a main factor of injury during longdistance running. This study will examine foot pressure distribution effects of marathon shoes during longdistance running, which have been developed by measuring Korean shoe lasts.

The methods of this study can be explained as below. Firstly, ten healthy males were picked as subjects to participate in this study. 10 healthy male subjects with an average age of 22.3 years $(\mathrm{SD}=0.5)$, weight of $71.5 \mathrm{~kg}$ $(\mathrm{SD}=6.0)$ and height of $173.1 \mathrm{~cm}(\mathrm{SD}=4.3)$ were recruited for this study. Secondly, the one equipment used for the study consist of a foot pressure device from Pedar-X, Germany and a treadmill from Pulse fitness, UK. Thirdly, the testing procedures involve each subject to test three different shoes by having running trials on a treadmill at a constant speed of $12.0 \mathrm{~km} /$ hour.

The pressure distribution data (contact area, maximum force, maximum peak pressure, maximum mean pressure)

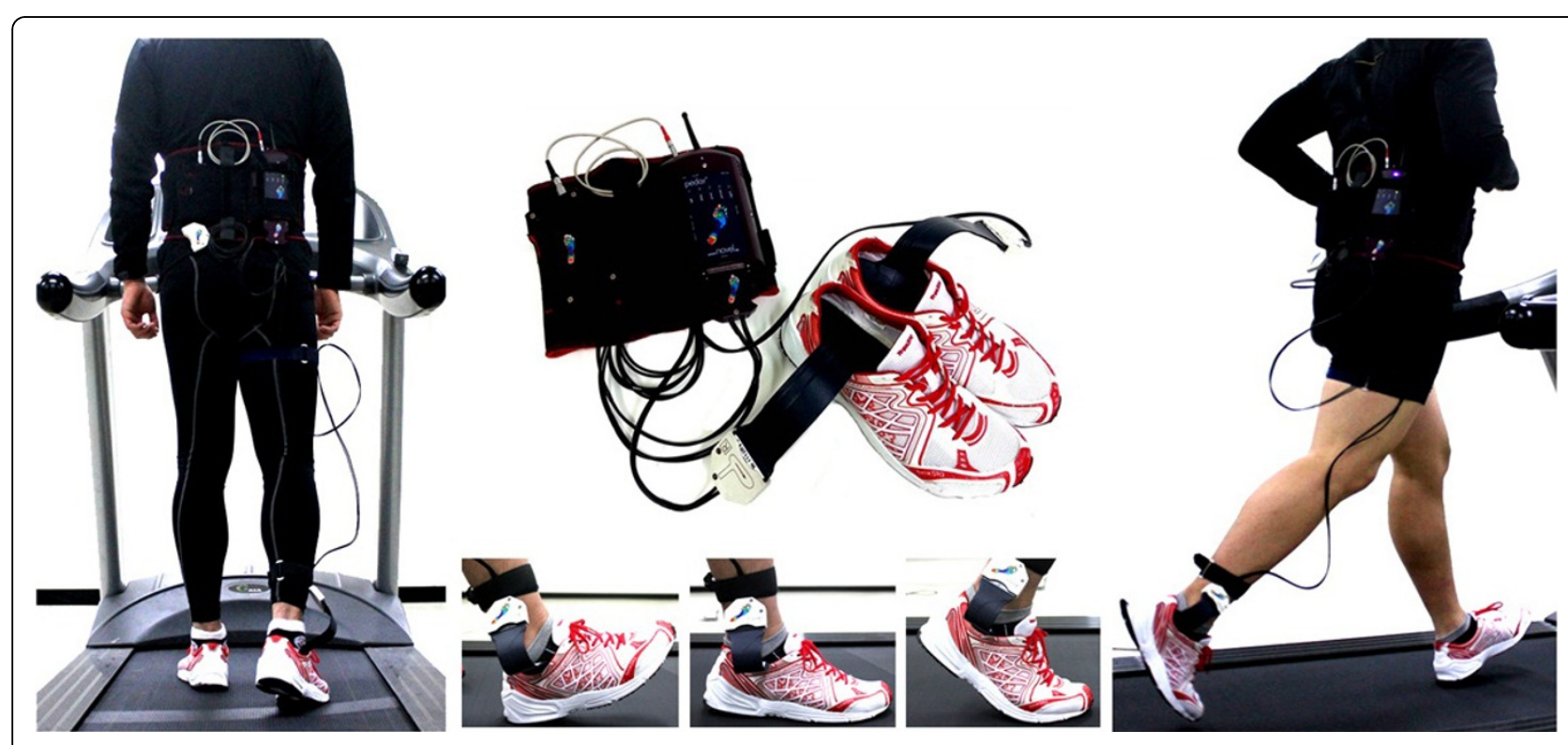

Figure 1 Marathon Shoes (NESTFIT Technology)

\footnotetext{
* Correspondence: sbpark@shoenet.org

${ }^{1}$ Footwear Biomechanics Team, Footwear Industrial Promotion Center, Busan, Korea

Full list of author information is available at the end of the article
} 
Table 1 Result of Foot Pressure (Marathon Shoes: Type A)

\begin{tabular}{|c|c|c|c|c|c|c|c|c|}
\hline \multirow[t]{2}{*}{ Mask } & \multicolumn{4}{|c|}{ Contact area $\left(\mathrm{cm}^{2}\right)$} & \multicolumn{4}{|c|}{ Maximum force $(\mathrm{N})$} \\
\hline & A & B & C & $p$-value & A & B & $\mathrm{C}$ & $p$-value \\
\hline Total & $156.62 \pm 23.25$ & $155.27 \pm 17.25$ & $156.92 \pm 12.07$ & 0.98 & $1,309.43 \pm 252.33$ & $1,369.60 \pm 183.88$ & $1,345.98 \pm 121.75$ & 0.78 \\
\hline Forefoot & $60.42 \pm 9.02$ & $60.99 \pm 7.12$ & $61.03 \pm 4.66$ & 0.98 & $746.65 \pm 170.96$ & $792.76 \pm 121.39$ & $728.42 \pm 101.16$ & 0.55 \\
\hline Midfoot & $54.40 \pm 9.13$ & $51.73 \pm 7.31$ & $54.08 \pm 5.67$ & 0.69 & $436.86 \pm 114.82$ & $398.41 \pm 105.88$ & $411.33 \pm 95.55$ & 0.71 \\
\hline Rearfoot & $41.04 \pm 5.32$ & $41.80 \pm 3.86$ & $41.07 \pm 3.22$ & 0.90 & $501.65 \pm 109.75$ & $530.39 \pm 96.21$ & $537.09 \pm 79.32$ & 0.68 \\
\hline \multirow[t]{2}{*}{ Mask } & \multicolumn{4}{|c|}{ Maximum peak pressure $(\mathrm{kPa})$} & \multicolumn{4}{|c|}{ Maximum mean pressure $(\mathrm{kPa})$} \\
\hline & $A$ & B & C & $p$-value & A & B & $\mathrm{C}$ & $p$-value \\
\hline Total & $298.03 \pm 85.12$ & $256.10 \pm 256.10$ & $266.04 \pm 266.04$ & 0.31 & $94.27 \pm 18.45$ & $95.94 \pm 11.20$ & $95.99 \pm 10.74$ & 0.95 \\
\hline Forefoot & $289.14 \pm 85.26$ & $248.23 \pm 41.31$ & $252.43 \pm 47.66$ & 0.28 & $119.79 \pm 28.58$ & $127.51 \pm 20.42$ & $118.60 \pm 16.84$ & 0.63 \\
\hline Midfoot & $147.34 \pm 43.97$ & $157.82 \pm 49.05$ & $166.41 \pm 43.38$ & 0.65 & $77.87 \pm 21.35$ & $75.85 \pm 19.14$ & $76.45 \pm 17.28$ & 0.97 \\
\hline Rearfoot & $185.35 \pm 68.01$ & $193.80 \pm 53.62$ & $207.45 \pm 52.65$ & 0.70 & $120.43 \pm 23.54$ & $126.65 \pm 22.14$ & $130.28 \pm 18.08$ & 0.59 \\
\hline
\end{tabular}

${ }^{*} p<.05$

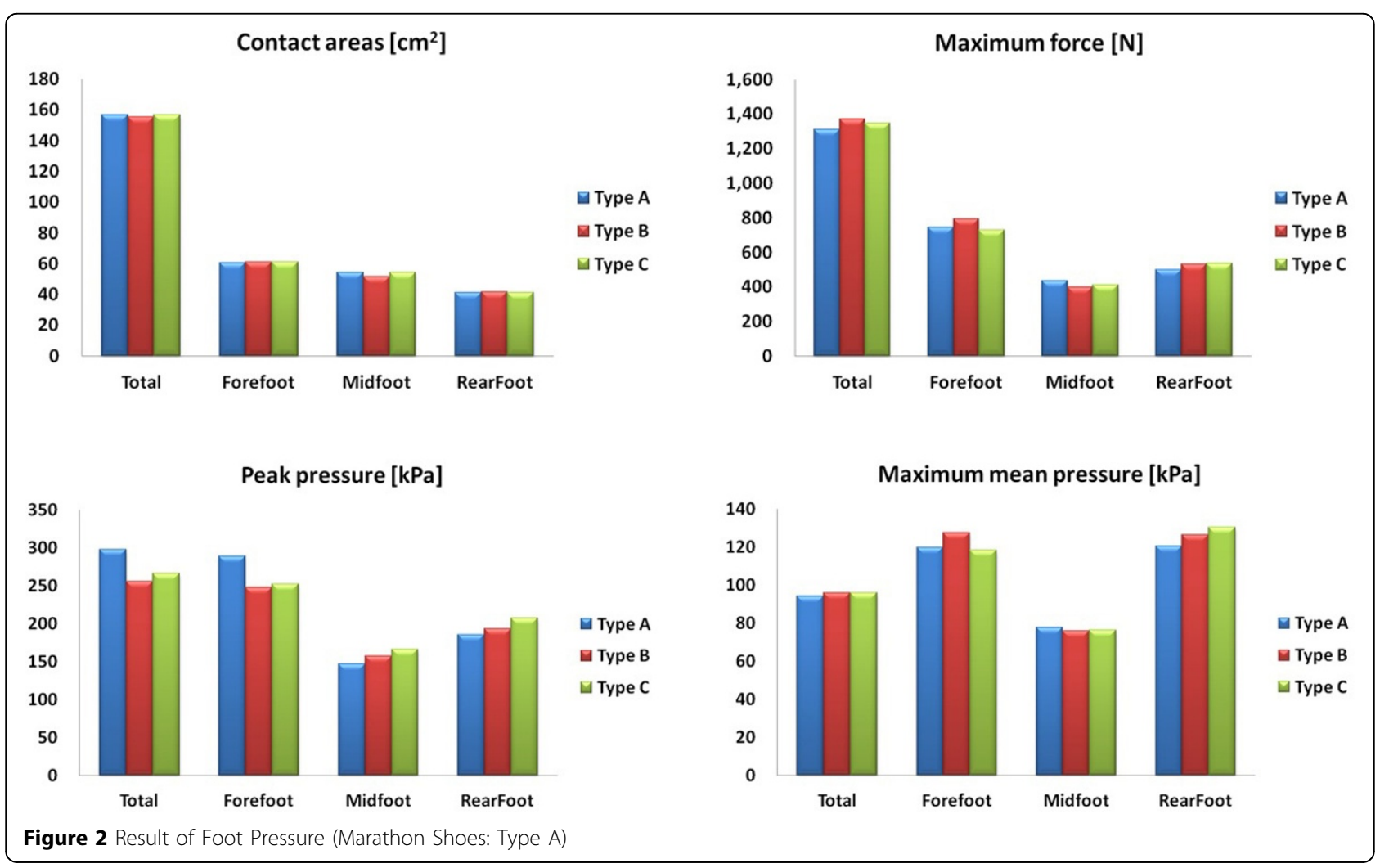

was collected by using a pressure device at a sampling rate of $100 \mathrm{~Hz}$. The statistical analysis was carried out by using the MINITAB R15 package, specifically One-way ANOVA $(\alpha=.05)$. Type A shoe has the lowest peak pressure at total mask. Generally, the Type A shoe had overall lower values for the maximum force and maximum mean pressure variables compared to Type $\mathrm{B}, \mathrm{C}$ shoe conditions.

In comparison with the control group: 1)The contact areas of foot (total) increased $0.87 \%$ than Type B, midfoot increased $5.17 \%$ than Type B and $0.59 \%$ than Type C. 2) The maximum force of foot (total) decreased $4.39 \%$ than Type B and $2.72 \%$ than Type C, rearfoot decreased $5.42 \%$ than Type B and $2.72 \%$ than Type C. 3)The maximum peak pressure of midfoot decreased $6.64 \%$ than Type B and $11.46 \%$ than Type C, rearfoot $4.36 \%$ than Type B and $10.66 \%$ than Type C. 4)The maximum mean pressure of foot (Total) decreased $1.74 \%$ than Type B and $1.79 \%$ than Type C, rearfoot decreased $36 \%$ than Type B and $10.66 \%$ than Type $C$.

As a result of analysis, it has been found that Type A has the lower maximum force (total) and maximum mean pressure (total) than Type B or C. Also, it has been found 
that Type A has the lower maximum force (rearfoot) and foot pressure (rearfoot) than Type B and Type C. In addition, it has been proved that the maximum force and maximum mean pressure of Type $A$ is lower than any other control groups so that it provides pressure distribution effects during long-distance running.

\section{Authors' details}

${ }^{1}$ Footwear Biomechanics Team, Footwear Industrial Promotion Center, Busan, Korea. ${ }^{2}$ Design Center, Treksta INC, Busan, Korea.

Published: 8 April 2014

\section{References}

1. Jose AR, Eduardo R: Scaling properties of marathon races. Physica A 2006, 365:509-520.

2. Karkoulias K, Habeos I, Charokopos N, Tsiamita M, Mazarakis A, Pouli A, Spiropoulos K: Hormonal responses to marathon running in non-elite athletes. European Journal of Internal Medicine 2008, 19:598-601.

doi:10.1186/1757-1146-7-S1-A122

Cite this article as: Park et al:: Biomechanical analysis of marathon

shoes applied to NESTFIT technology. Journal of Foot and Ankle Research 2014 7(Suppl 1):A122.

\section{Submit your next manuscript to BioMed Central} and take full advantage of:

- Convenient online submission

- Thorough peer review

- No space constraints or color figure charges

- Immediate publication on acceptance

- Inclusion in PubMed, CAS, Scopus and Google Scholar

- Research which is freely available for redistribution

Submit your manuscript at www.biomedcentral.com/submit 